\title{
Learning Styles: An Overview of the Felder-Silverman's Model and Measure
}

\author{
Asfandeyar Fida ${ }^{1}$ \\ Dr. Abdul Ghaffar ${ }^{2}$
}

\begin{abstract}
Individual differences are of particular concern for educators in the teachinglearning process. Besides physical and social facets, it includes interest, motivation, aptitude, attitude etc. One of the recently focused such facet is learning style. Learning style denotes an individual's instinctive pattern of acquiring knowledge and processing information. Learning styles are significant to education and curriculum. There are various models and measures of learning styles like Kolb (1984), Honey and Mumford (1982), Sousa's (1995) Visual, Auditory and Kinesthetic (VAK), Fleming's (1995) Visual, Auditory, ReadWrite and Kinesthetic (VARK) and Felder and Silverman's Model (1988). One of the most comprehensive and widely used conceptions is Felder-Silverman's model of learning styles. The dimensions of this model consist of four continuums known as sensing-intuitive, active-reflective, visual-verbal and sequential-global. Also, the facets of this model are analogous to the facets of other conceptions of learning styles. The learning style dimensions of this model are determined through a scale known as Index of Learning Styles (ILS). This tool has shown ample validity and reliability. In Pakistan, research on learning styles is scarce. Also, there was no evidence of using this model in any research inquiry in the local context. The aim of this paper was to give a detailed description of Felder-Silverman Model and Measure. Similarly, it was planned to report the psychometric features of the ILS. Furthermore, it was also intended to persuade the researchers to use this tool for research.
\end{abstract}

Keywords: Learning style, Felder-Silverman Model, Index of Learning Styles

\footnotetext{
${ }^{1} \mathrm{PhD}$ (Education) Scholar, Abdul Wali Khan University, Mardan

Email. asfand_chd@yahoo.com

${ }^{2}$ Assistant Professor, Abdul Wali Khan University, Mardan
} 


\section{Introduction}

Learning is an inclusive procedure that considers many factors like intelligence, motivation, goal, aptitude, interest, memory etc. Similarly, individual difference is also an important component of learning. These differences exist in the people's physique, sociability, affective attributes and cognitive characteristics (Din, 2009). Individual differences appear in different shapes. Gender, physique, age, ethnicity etc. are explicit differences while intelligence, memory, early experiences and other behavioral attributes are latent differences (Din, 2009; Al- Azawei \& Badii, 2014).

Students are different in terms of processing information. They prefer learning practices that they found appealing and adequate, for instance, a student may take notes of a topic from History, but his classmate prefers to watch a documentary about the same area or topic (Kanninen, 2009). Likewise, some learners like to perform tasks while others learn better through listening. Similarly, some learners take interest in learning through visual modality (Din, 2009). This particular preference to learning practices is known as leaning styles. Cassidy (2004) holds that learning styles denote particular approaches to accomplish academic errands.

Learning styles are worth to consider in the process of schooling. Apparently, students having learning activities matching to their respective learning styles perform better than those who face a mismatch. Collinson (2004) holds that learning style is an established factor of getting better results from the instructional procedures. Many researchers are of the view that learning styles have a vital role in the process of education. Students will face problems if their learning styles do not complement with the instructional mode of their teachers (Felder \& Silverman, 1988; Felder \& Spurlin, 2005).

Researchers have identified various models of learning styles (see, e.g. Kolb, 1984; Honey \& Mumford, 1992; Fleming, 1995 and Felder-Silverman, 1988; etc.). The Felder-Silverman's proposed model is a comprehensive and widely used model. This study aimed at to provide a theoretical framework of FelderSilverman's Model and Measure. It is also intended to encourage implication of this model for research investigation in the local context.

\subsection{Objectives of the Study}

In Pakistan, there are a few studies on learning styles. The researcher has not found any study based on Felder-Silverman's model. Therefore this study aimed at:

1. To give a detailed description of the Felder - Silverman's Model of Learning Styles. 
2. To highlight the instrument of learning styles based on Felder-Silverman's model.

3. To review the validity and reliability of the Index of Learning Styles (ILS).

4. To persuade researchers to employ this model and measure for investigations.

\subsection{Significance of the Study}

This study has included description of the salient features of the FelderSilverman's model. The facets of this model could assist teachers in making instructional and assessment plans. It could also help curriculum planners to consider the facets of learning styles in devising curriculum, subject matter and assessment procedures. The facets of this model have been thoroughly discussed. Further, the status of Index of Learning Styles (ILS) is discussed as a valid and reliable instrument. In addition, this study has suggested guidelines for future investigation.

\section{Review of Literature}

\subsection{Learning Styles}

Learning style is an important factor of learning. There is slight variation in the definitions of learning styles. The term 'style' helps to identify how individuals are similar to or different from each other with respect to their learning approaches (Din, 2009).The leading definition of learning style, which is preferred by ELSIN association (cited in Peterson, Rayner \& Armstrong, 2009b), is a person's preferred manner of behavioral and cognitive reactions towards learning errands. Learning styles are thought to be flexible as they are liable to changes with changes in environment. Learning style is not a fixed and isolated term. It is not totally independent of other terms or variables (Kanninen, 2009). Instead, a specific learning style is formed through a conjugation of intellectual, affective and behavioral traits. These elements influence how an individual will sense, interact and respond to the learning stimuli. The exclusive combination of these traits determines how an individual will learn in a particular style. It results in different approaches from different students in a similar learning situation (Gordon 1998 as cited in Din, 2009). Further, preferring one learning style does not mean that a person has no inclination for other styles. An individual with preference for particular learning style may bring into play elements of other styles too. Students with diverse styles of learning may integrate them to get an appropriate concoction for every learning opportunity (Kanninen, 2009).

\subsection{Learning Styles and Cognitive Styles}

The terms 'cognitive styles' and 'learning styles' are assumed to be compatible (Cassidy, 2004; Din, 2009). They have been used in tantamount in research investigations (Evans \&Charlesworth2010; Evans \& Sadler- Smith 
2006). It is difficult to draw a line of distinction between these terms (Cassidy, 2004). Gordon (1998 as cited in Din, 2009) believes that these are inclusive concepts and contain facets of cognition, behavior and affection. Further, cognitive style denotes the discrepancies among individuals on the basis of how they execute information. It is allied to an individual's cognitive system. Cognitive styles represent a person's preferred approach to execute information. It is assumed to be somewhat stable and probably innate (Peterson et al., 2009b). However, Din (2009) viewed that cognitive style resides in a human mind and has no patent association with the environment. While learning style is environment based and has evident association with motives, wants, hassles, difficulties and effects of the surroundings. In addition, Peterson et al. (2009b) considered learning styles as top-down strategies that focus on the students and learning assignments. Whereas, cognitive styles are assumed to be bottom-up i.e. from inner to outer mode.

Since 1980, learning styles have been a focus of many researchers. As a result many models and instruments have been introduced. Some well-known models are Kolb (1984), Honey and Mumford (1982), Sousa's (1995) VAK (Visual, Auditory and Kinesthetic) and Fleming's (1995) VARK (Visual, Auditory, Read-Write and Kinesthetic) and Felder and Silverman Model (1988). Many researchers (e.g. Cassidy, 2004, Din, 2009) attempted to classify the models of learning styles. Din (2009) has arranged learning models into three wide categories namely perceptual modalities, information process and personality attributes.

\subsection{Felder and Silverman Model of Learning Style}

Richard M. Felder and Linda K. Silverman put forward their model of learning styles in 1988 (Din, 2009).They considered learning style as an approach with which pupils acquire and apply new concepts. It describes how people obtain, interrelate and reasonably retort to the learning stuff (Felder \& Silverman, 1988; Felder \& Brent, 2005; Felder \& Spurlin, 2005).At first this model was made known to the graduates of Engineering (Zywno, 2003).Felder and Silverman (Felder, 1993; Felder and Silverman, 1988) suggested four factors of their learning style model. Each dimension embodies the preferred manner of an individual's learning (Tanner \& Allen, 2004). These dimensions are helpful in addressing the multiplicity of learning styles and their relation with the pedagogical practices(Tanner \& Allen, 2004).These facets consist of: type of information preferred either through 'sensing or intuiting,' modality to acquire information through 'visual or verbal' mode. Primarily, this model contained five factors (Zywno, 2003): 
(a) The active-reflective dimension is subsumed under the 'processing of information.'

(b) Sensing-intuitive element belongs to the 'perceiving of information' factor.

(c) Visual-verbal aspect comes under the 'input of information' facet.

(d) Sequential-global is considered under the 'understanding of information' factor.

(e) Inductive-deductive dimension falls under the 'organization of data' factor.

Felder advocated the facet of 'organization' for teaching only. It is not estimated through index of learning styles (Zywno, 2003). The facets of this model are not distinct categories rather they are laying on a continuum. A person's score on any dimension could be located anywhere between two extremes. It implies that favoring one aspect, such as visual, does not indicate the individual has no inclination towards verbal modality at all (Fillipidis \& Tsoukalas, 2009).

\subsubsection{Active or Reflective}

This dimension is subsumed under the category of information processing. Active learners are dynamic people who like performing activities and trying things out (Din, 2009; Leithner, 2011; Fillipidis \& Tsoukalas, 2009). They are fond of 'learning by doing' and carrying out activities in groups (Mestre, 2010; Fillipidis \& Tsoukalas, 2009). They may describe, apply or operate the learning stuff. They find it hard to attend the long lecture sessions (Mestre, 2010). On the other hand, reflective learners concentrate on and contemplate about the objects, ideas or issues presented to them. They think over ideas for a long time before conceptualizing them (Din, 2009).They like to work and study in isolation (Leithner, 2011; Mestre, 2010; Bacon, 2004) or with a single known mate (Ultanir, Ultanir \& Temel, 2012). They like instruction through lectures and seminars (Din, 2009).

\subsubsection{Sensing or Intuitive}

This factor considers how people 'perceive' information (Leithner, 2011). Sensing learners have pragmatic approach. They like factual data and workable ideas (Fillipidis \& Tsoukalas, 2009). They prefer conventional and stereo-type techniques to address problems. Similarly, they like courses which have marked association with everyday life. They also go well with extensive data (Mestre, 2010; Ultanir, et al., 2012).Sensing learners become upset with challenging tasks (Mestre, 2010). They have usually concerns about the effectiveness of academic practices and programs. They also dislike to be assessed in vague and embedded concepts and ideas (Din, 2009).

On the contrary, intuitive learners favor abstract conceptions and originality. They are keen to identify associations and likelihoods among ideas (Leithner, 
2011; Fillipidis \& Tsoukalas, 2009). They are also highly interested in novelty. Computation and rote learning activities are unappealing to them (Mestre, 2010).Intuitive learners are more innovative as compared to their opposites (Ultanir, et al., 2012).They averse the conventional practices and welcome changes and challenge (Din, 2009).

\subsubsection{Visual or Verbal}

The visual-verbal preference belongs to the 'input' factor (Leithner, 2011). Visual learners are inclined to learn from visual data like figures, images, charts, tables etc. (Fillipidis \& Tsoukalas, 2009; Ultanir, et al., 2012). They have better capacity to observe. They do not like verbal instructions (Din, 2009). On the other hand, verbal learners are superior in learning from oral narration and written descriptions and listening (Mestre, 2010; Fillipidis \& Tsoukalas, 2009; Leithner, 2011). They are also known as auditory learners as they are superior in dealing information explained through spoken words and verbal details. They also take interest in lengthy periods of lectures and discussion sessions (Din, 2009).

\subsubsection{Sequential or Global}

The sequential-global facet is subsumed under the 'understanding' facet (Leithner, 2011). Sequential learners adapt a stepwise approach for comprehension. They study in a linear format and learn step by step. They do not ignore minute details. One step leads to another on rational basis (Fillipidis \& Tsoukalas, 2009; Mestre, 2010; Din, 2009). They need a valid connection between different aspects of an idea (Din, 2009). They are keen to get extensive details about a concept (Ultanir, et al., 2012).

To the contrary, global learners focus on the whole view and like to understand in huge bounds (Leithner, 2011). They ignore minute details (Fillipidis \& Tsoukalas, 2009; Bacon, 2004) and study randomly. They frequently disregard the relationships among ideas and rush to the conclusions (Mestre, 2010; Ultanir, et al., 2012). They can rapidly resolve complex problems and configure objects and ideas in an innovative format (Mestre, 2010).

\subsection{Equivalency with Other Models}

The facets of Felder-Silverman Mode correspond with certain facets of other conceptions (Felder \& Spurlin, 2005; Perna, 2011). For instance, the activereflective dimension is existed in Kolb's Model (Kolb, 1984; 1993). It is also alike to the extravert-introvert dimension of Myers-Briggs type indicator (MBTI) (Lawrence, 1993). The sensing-intuitive continuum is also existed in the MyersBriggs type indicator (MBTI). It is also equivalent to the concrete-abstract element of Kolb's model. The active-reflective and visual-verbal elements are 
also matching with the compositions of modality theory and neuro-linguistics (Fillipidis \& Tsoukalas, 2009).

\subsection{Index of Learning Styles}

Felder and Solomon (n.d.) devised an instrument based on Felder-Silverman (1988) model for determining learning styles. It was known as index of learning styles (ILS). In 1996, the printed form of the ILS was placed on the world-wideweb. The online form was initiated in 1997 (Felder \& Solomon, n.d.). It was intended to facilitate the learners to fill in the questionnaire online and get immediate feedback (Perna, 2011). The index of learning style is free of cost for noncommercial purposes, for instance, researchers who wish to use it for investigation. Similarly, teachers who want to employ it for instructional purposes and individuals who desire to find their own learning modes (Ultanir, et al., 2012).

The ILS describes only the preference of a particular learning mode. It does not indicate the strength or weaknesses of a person. The ILS identifies the skills of an individual on particular learning mode. It does not consider the group comparison (Felder \& Spurlin, 2005). This instrument classifies students on either side of each of four continuums based on their preferences i.e. either on visual or verbal. An individual may also be placed between the two extremes (Felder \& Spurlin, 2005; Zywno, 2003; Clarke, Lesh, Trocchio \& Wolman, 2010). At the beginning, this tool was dispensed to a sample of engineering students (Ultaniir, et al., 2012). Generally, the scale consists of 44 simple statements with each statement having two responses represented by options ' $a$ ' and ' $b$.' The respondents have to tick either option ' $a$ ' or ' $b$ ' in accordance with their preferences (Van Zwanenberg, Wilkinson, \& Anderson, 2000; Green \&Sammons, 2014; Graf, Viola, Leo \& Kinshuk, 2007). This scale determines a respondent's preferences for one or other aspect of all four dimensions(Felder \& Spurlin, 2005; Zywno, 2003; Clarke et al., 2010).There are 11 questions for each dimension of learning styles which determine an individual's position on each dimension (Leithner, 2011; Graf, et al. 2007).

\subsection{Validity and Reliability of ILS}

Validity and reliability are the two major attributes to be considered for any instrument to be psychometrically sound. Several investigators (Zwyno, 2003; Felder \& Spurlin, 2005) have shown that ILS is a valid and reliable instrument and could be used for studying learning styles. The ILS has adequate test-retest reliability. Alumran (2008) found the test-retest reliability was calculated to be 0.8 with an interval of 2 weeks for all facets of ILS. Ultanir et al. (2012) found the test-retest consistency in the range of 0.51 to 0.89 with an interval of 3 months using a sample of non-native English speakers. Felder \& Spurlin (2005) 
computed the test-retest reliability and found it to be in the range of 0.7 to 0.9 with a time gap of 28 days.

Several studies have computed low level of internal consistency of ILS, for instance, Van Zwanenberg et al. (2000) reported the internal consistency in the limits of 0.41 to 0.65. Similarly, Livesay, Dee, Nauman \& Hites (2002) proclaimed alpha to be existing between 0.54 and 0.72 ; although, they reported high level of test-retest consistency. Similarly, Felder \& Spurlin (2005) have reported the internal consistency being in the limits of $0.55-0.76$ while Zywno (2003) estimated it in the range of $0.53-0.70$ for all four facets. However, other researchers presumed this level for achievement scales, while for attitudinal scale, an internal consistency of 0.5 is accepted (Tuckman, 1999).

ILS is also a valid instrument. Zywno (2003) identified that ILS has the attribute of construct validity by analyzing consecutive cohort studies. It was also shown that there were no meaningful distinctions between the average scores of the students in the successive years which confirm the construct validity. Similarly, this instrument also bears convergent construct validity (Felder \& Spurlin, 2005), as engineering students of different areas and in different periods have shown numerous common characteristics (Zwyno, 2003). Similarly, the discriminant validity of ILS has also been confirmed by showing meaningful difference in results from populations with diverse attributes. For instance, Van Zwanenberg et al. (2000) have shown a meaningful difference of learning styles between students of Business and Engineering. Similarly, researchers (Wetzel \& Harmeyer, 1997; Zywno, 2003) have made a comparison between learning styles of learners and faculty members by employing ILS and have detected vital differences in distribution of learning styles.

Zywno (2003) is of the opinion that ILS meets the adequate standard of construct validity and reliability. In addition, Felder (2005) asserted that the ILS has been validated in ten universities of four countries by studying English oriented Engineering students. Further, feedback from the learners and factor analysis endorse its validity. To conclude, ILS is an approved instrument in the research arena regardless of some criticism (Akbulut \& Cardak, 2012; Al-Azwei \& Badii, 2014).

\subsection{Scoring and Interpreting the Index of Learning Styles}

The results obtained through ILS have been scored and interpreted in two ways by researchers. For each continuum, such as visual-verbal, options ' $a$ ' of the respective questions signify responses for 'visual' facet while options ' $b$ ' stands for 'verbal.' For each factor, there are 11 questions. The preferences of respondents are either indicated in values from $11 \mathrm{a}$ to $11 \mathrm{~b}$ or in the digits from 11 to +11 (Green \& Sammons, 2014; Graf, 2007). 
In the first, when (-1) and (+1) format of scoring is used (Graf, et al., 2007). The option ' $a$ ' carries $(+1)$ and option ' $b$ ' carries $(-1)$ for each item. When a respondent selects an option ' $a$ ', for instance, on the visual-verbal facet, visual score is increased by $(+1)$ while the opposite, the verbal facet is decreased by $(-1)$ and is subtracted from the opposite i.e. verbal preferences (Graf, et al., 2007; Green \& Sammons, 2014). On each of four dimensions, the scores of students fall between -11 to +11 (Leithner, 2011). Learning styles preferences on the extremes, i.e. -11 or +11 are assumed to be stronger, for example, on sequentialglobal scale, +11 stands for strong sequential preference while -11 represent strong global tendencies (Green \& Sammons, 2014).Further, in interpreting, for example, active-reflective scores, 0 or 1 , represents a strong reflective tendency, 2 or 3 symbolizes a moderate reflective preferences, 4 or 5 signifies a mild favoritism for reflective, 6 or 7 shows mild active preferences, 8 or 9 signifies a moderate tendency for active while 10 or 11 stands for strong active inclination (Felder \& Spurlin, 2005).

In the second approach, when $11 \mathrm{a}$ and $11 \mathrm{~b}$ scoring procedure is adapted. Then the score is computed by adding up total ' $a$ ' response and total ' $b$ ' responses. If the sum of ' $b$ ' responses is less than the sum of ' $a$ ' responses then it is subtracted from the total of ' $a$ ' responses and vice versa (Van Zwanenberg, et al., 2000).To put it simple, all the 'a' and ' $b$ ' responses for an aspect, say visualverbal are added up. The sum of smaller score is subtracted from the larger sum and final score is obtained. The final score is interpreted as:

$\begin{array}{lll}\text { Score } & 1 \text { or } 3 & \text { Balanced between two aspects } \\ 5 \text { or } 7 & \text { Moderate preferences } \\ 9 \text { or } 11 & \text { Strong preferences }\end{array}$

If the score of an individual is $5 \mathrm{a}$ on active-reflective dimension then he has moderate preferences for active learning mode. Similarly, if an individual scores $9 \mathrm{~b}$ on the sequential global dimension then he has strong preferences for global style. Finally if the score is between 1 and 3 then the preferences of the individual is balanced on the sequential-global dimension (Felder \& Solomon, n.d.).

\section{Conclusions}

The above discussion revealed that the Felder-Silverman's Model is very broad and comprehensive. It has got sufficient theoretical details. This model is also analogous to various other conceptions. Further, it does not declare learning styles as something absolute or distinct. It shows not only the existence but also the degree to which an individual possesses a particular learning style. In 
addition, it denotes the learning styles on a continuum and an individual could aptly rate himself at any position on the continuum. It shows the flexibility of this conception and turns it superior over other models.

The facets of Felder-Silverman model are estimated through a comprehensive measure, known as Index of Learning Styles. It is a valid and reliable tool. It has sufficient internal consistency and good test-retest reliability. Furthermore, this tool has good construct validity. It has also the validity to discriminate. This measure has a scoring procedure and terms for interpretation. In a nutshell, this model is of vital significance for researchers, educationists and evaluators.

\section{Recommendations}

Research on learning styles is scarce in Pakistan. This model and measure would provide an important avenue for researchers to explore it further. Researchers could validate this tool in the local context in original form as well as in its translated version. Similarly, researchers could apply this model and measure to various levels of education. Furthermore, the curricula, instructional and assessment procedures could be evaluated keeping in view the facets of this model. The index of learning styles could also be used in collaboration with other tools of learning styles. Similarly, learning styles could also be used with other relevant variables for correlational investigations. Researchers may also consider developing new tools keeping in view the facets of this model.

Teachers may also consider this model for instructional purposes. It is evident that teaching-learning process is incomplete without proper consideration and implementation of learning styles in different educational contexts. Similarly, it is equally important for students' assessment. For this purpose, the school administration may guide teachers through workshops and seminars on how to utilize this model for instructional and assessment purposes.

\section{References}

Akbulut, Y.,\& Cardak, C. S. (2012). Adaptive educational hypermedia accommodating learning styles: A content analysis of publications from 2000 to 2011. Computers \& Education, 58(2), 835- 842.

Al-Azawei, A.,\& Badii, A. (2014). State of the art of learning styles-based adaptive educational hypermedia systems. International Journal of Computer Science and Information Technology, 6(3), 1-19.

Alumran, J. I. A. (2008). Learning styles in relation to gender, field of study, and academic for Bahraini university students. Individual difference research, 6 (4), 303-316. 
Bacon, D. R. (2004). An examination of two learning style measures and their association with business learning, Journal of Education for Business, 79(4), 205-208.

Cassidy, S. (2004). Learning style: an overview of theories, models and measures. Education Psychology, 24 (4), 419-444.

Collinson, E. (2004). A survey of elementary students' learning style preferences and academic success. Contemporary Education, 71(4), 42-49.

Clarke, T. A., Lesh, J. J., Trocchio, J. S. \&Wolman, C. (2010). Thinking styles: teaching and learning styles in graduate education students. Educational Psychology: An International Journal of Experimental Educational Psychology, 30(7), $837-848$.

Din, M. (2009). A study in indices of discrepancy between students' learning styles and their actual grade achievement at masters' level (Unpublished doctoral thesis). National University of Modern Languages, Islamabad.

Evans, C., \&. Sadler-Smith, E. (2006). Learning styles. Education and Training, 48(2), 77-83.

Evans, C., Cools, E. \& Charles worth, Z. M. (2010). Learning in higher education - how cognitive and learning styles matter. Teaching in Higher Education, 15(4), $467-478$.

Felder, R.M., and Silverman, L.K. (1988). Learning and teaching styles in engineering education. Engineering Education, 78(7), 674-681.

Felder, R.M. (1993). Reaching the second tier: learning and teaching styles in college science education. Journal of College Science Teaching, 23(5), 286-290.

Felder, R., \& Brent, R. (2005). Understanding student differences. Journal of Engineering Education, 94(1), 57-72.

Felder, R.M., \& Solomon, B.A. (n.d.). Index of Learning Styles. Retrieved April, 22, 2015 from http://www.ncsu.edu/felder-public/ILSpage.html

Felder, R.M., \& Spurlin, J. (2005). Applications, reliability, and validity of the index of learning styles. International Journal of Engineering Education, 2l(1), 103-112. 
Filippidis, S.K. \& Tsoukala, I. A. (2009). On the use of adaptive instructional images based on the sequential-global dimension of the Felder-Silverman learning style theory. Interactive Learning Environments, 17(2), 135-150.

Fleming, N. (1995). I'm different; not dumb: Modes of presentation (VARK) in the tertiary classroom. Paper presented at the annual conference of the Higher Education Research and Development Society of Australasia, Rock Hampton, Australia.

Graf, S., Viola, S. R., Leo, T. \& Kinshuk (2007). In-depth analysis of the FelderSilverman learning style dimensions. Journal of Research on Technology in Education, 40(1), 79-93. doi.10.1080/15391523.2007.10782498

Green, A. J. \& Sammons, G. E. (2014). Student learning styles: assessing active learning in the hospitality learners model. Journal of Hospitality \& Tourism Education, 26(1), 29-38.

Honey, P., \& Mumford, A. (1982). The manual of learning styles. Maidenhead: Peter Honey Publications.

Kanninen, E. (2009). Learning styles and e-learning (Unpublished master dissertation). Tampere University, Tampere. Retrieved on April, 28, 2015 from https://scholar.google.com.pk/scholar?q=learning+styles+and+eearning+kanninen\&h

Kolb, D.A. (1984). Experiential learning: experience as the source of learning and development. Englewood Cliffs, NJ: Prentice-Hall.

Kolb, D. A. (1993). LSI-IIa: Self-scoring inventory and interpretation booklet. Boston: McBer\& Company.

Lawrence, G. (1993). People types and tiger stripes (3rd Ed.). Gainesville, FL: Center for Applications of Psychological Type.

Leithner, A. (2011). Do student learning styles translate to different testing styles? Journal of Political Science Education,7(4), 416-433.

Livesay, G.A., Dee, K.C., Nauman, E.A. \& Hites L.S. (2002). Engineering student learning styles: A statistical analysis using Felder's index of learning styles. Presented at the 2002 Annual Conference of the ASEE, Montreal, Quebec.

Mestre, L. S. (2010). Matching up learning styles with learning objects: what's effective? Journal of Library Administration, 50(7-8), 808-829. 
Peterson, E.R., Rayner, S.G. \& Armstrong, S.J. (2009b). Herding cats: In search of definitions of cognitive styles and learning styles. Retrieved on February 14, 2009, from http://www.elsinnews.com

Perna, J. (2011). Learning styles and their effect on student learning (Senior honors theses). Eastern Michigan University, Michigan.

Sousa, D. (1995). How the brain learns. Reston, VA: National Association of Secondary School Principals.

Tanner, K. \& Allen, D. (2004). Approaches to Biology teaching and learning: Learning styles and the problem of instructional selection - engaging all students in science courses. Cell Biology Education, 3, 197-201.

Tuckman, B.W. (1999). Conducting educational research (5 ${ }^{\text {th }}$ Ed.). (n.p): Wadsworth Group.

Ultanir, E., Ultanir, Y. G. \&Temel, O. G. (2012). The examination of university students' learning styles by means of Felder-Silverman index. EğitimveBilim, Education and Science, 37(163), 29-42.

Van Zwanenberg, N. V., Wilkinson, L. J. \& Anderson, A. (2000). Felder and Silverman's index of learning styles and Honey and Mumford's learning styles questionnaire: How do they compare and do they predict academic performance? Educational Psychology: An International Journal of Experimental Educational Psychology, 20(3), 365-380.

Wetzel, K.C. \& Hameyer, K.M. (1997). Success in low-level and high-level Mathematics courses in Undergraduate Engineering University as a correlate to individual learning style. Proceedings of the 27thASEE/IEEE Frontiers in Education Conference, Pittsburgh, PA, USA.

Zywno, M.S. (2003). A contribution to validation of score meaning for FelderSoloman's index of learning styles. Proceedings of the 2003 Annual ASEE Conference, Washington, DC: ASEE. 